\title{
(2) \\ Advocating for equity during the pandemic
}

\section{OPEN ACCESS}

'Department of Emergency Medicine, Massachusetts General Hospital, Boston, Massachusetts, USA ${ }^{2}$ Center for Social Justice and Health Equity, Department of Emergency Medicine Massachusetts General Hospital, Boston, Massachusetts, USA

${ }^{3}$ Department of Emergency Medicine, Brigham and Women's Hospital, Boston, Massachusetts, USA ${ }^{4}$ Health Policy Research and Translation Fellow, Department of Emergency Medicine, Brigham and Women's Hospital, Boston, Massachusetts, USA

${ }^{5}$ Office of Inclusion, Diversity, Equity and Social Justice, Department of Emergency Medicine, Brigham and Women's Hospital, Boston, Massachusetts, USA ${ }^{6}$ The Family Van, Harvard Medical School, Boston, Massachusetts, USA

\section{Correspondence to} Dr Onyinyechi F Eke, Emergency Medicine, Massachusetts General Hospital, Boston, MA 02114, USA:

oeke@mgh.harvard.edu

Received 10 September 2020 Revised 20 November 2020 Accepted 5 March 2021 Published Online First 26 March 2021

\author{
Onyinyechi F Eke (10, ${ }^{1}$ Alister Martin, ${ }^{2}$ Hazar Khidir, ${ }^{1,3}$ Onyeka Otugo, ${ }^{4}$ \\ Andrew Marshall, ${ }^{5}$ Joanne C. Suarez, ${ }^{6}$ Wendy L. Macias-Konstantopoulos ${ }^{2}$
}

\begin{abstract}
In response to an imminent surge in COVID-19 cases, the state of Massachusetts (MA) released its Crisis Standards of Care (CSC) guidelines in April 2020. A small group of Boston healthcare providers, community members, lawyers, ethicists and disability advocates brought to bear our collective strengths to forge a formidable coalition now known as the Massachusetts Coalition for Health Equity, to champion the rights of marginalised groups that would be adversely affected by the implementation of the original MA CSC guidelines. In this coalition, members of marginalised communities were adequately represented, led discussions on the implications of implementing inequitable elements of the CSC guidelines and actively involved in creating an alternative framework. In this article, we discuss the process of building a coalition whose concerted advocacy efforts led to the revision of the MA CSC guidelines.
\end{abstract}

\section{BRIEF INTRODUCTION}

As the USA prepares for a second surge in COVID-19 cases, hospital resources needed to treat critically ill patients with COVID-19 like ventilators and intensive care unit beds may become so scarce that the need to ration these resources may become unavoidable. Many states released Crisis Standards of Care (CSC) guidelines, the official protocols that have helped hospitals allocate scarce critical care resources. Many of these guidelines, however, are fundamentally flawed and threaten to potentiate the long-standing health inequities exposed and exacerbated during this pandemic. We believe that healthcare consumers and patient advocates can champion more equitable statewide guidelines. As we have learnt from our experience in Massachusetts (MA), coalition-building can be a mechanism for driving rapid change in healthcare policy. In this article, we describe the steps taken to form our coalition and specific strategies carried out to push for change in the context of Massachusetts CSC guidelines as well as challenges faced and future directions.

\section{BUILDING AN EQUITY ADVOCACY COALITION}

On April 7, 2020, in anticipation of the peak of the initial surge of the COVID-19 pandemic, the Massachusetts Department of Health released CSC guidelines that included consideration of patients' chronic medical conditions. These guidelines, aimed at appropriately rationing precious medical resources, would have certainly placed individuals from communities of colour and individuals with disabilities at a disadvantage. In an effort to advocate for health equity within the State's guidelines, we formed a coalition. We first established a representative core group of diverse stakeholders and community members with expertise in clinical medicine, legislative action, bioethics and community advocacy. We then sought to integrate the best available evidence towards the creation of an alternative set of guidelines that was formed in partnership with disability rights advocates, local patient advocacy groups, members of the Black and Brown community and public health experts. After the formation of this core group and the careful formation of evidence-based alternative policies, we sought to initiate legislative coalition building with local state and city lawmakers. Finally, we engaged the media and attempted to educate the public through social media and earned media in an effort to raise awareness of this impending health equity crisis. As media coverage increased, we simultaneously continued to build coalitions with national politicians who emerged as allies for this work. On 20 April, the revised state guidelines released reflected significant changes based on input from our core group and our allied partners.

\section{Establish a representative core group}

When the Massachusetts Department of Health released their CSC guidelines on 7 April 2020 in anticipation of the first surge that hit the USA, these guidelines included consideration of patients' chronic medical conditions (eg, heart disease, chronic kidney disease, diabetes) as negative factors in determining which patients get priority for resources. Aware of the historical structural inequities that have led to an increased baseline prevalence of these conditions in minority populations, we immediately recognised that the inclusion of chronic conditions in CSC guidelines would almost certainly disproportionately impact communities of colour.

To mobilise for changing the guidelines, we used an advocacy coalition framework, ${ }^{1}$ synergising the power of diverse members to achieve a common goal. As frontline physicians of colour in Bostonarea emergency departments, we saw first-hand how African American and Latinx patients were bearing the brunt of the morbidity and mortality associated with COVID-19 infection and the potential of our State CSC guidelines to worsen racial health disparities. We subsequently identified individuals with expertise in legislative action, bioethics and community advocacy who would also be negatively impacted by the guidelines, including disability rights groups with strong track records of effective patient advocacy and individuals representing communities of colour. Together, we crystallised our mission and asserted our collective authority
To cite: Eke OF, Martin A, Khidir $\mathrm{H}$, et al. BMJ Leader 2021:5:127-129. 
under a nonpartisan and cross-sectoral group, the Massachusetts Coalition on Health Equity (MCHE).

\section{Integrate best available evidence}

Recognising that concerns regarding the CSC guidelines would be better received when delivered in conjunction with a viable alternative, our group of physicians, community members and patient advocates undertook an alternative policy creation process to design a new framework for the State's CSC guidelines that centred on health equity. This policy reform work was influenced by research of alternative frameworks proposed by other states and by alternative ethical frameworks. The overall ethical framework, based on justice principles, is grounded on saving the most lives and life years. Following a comprehensive review of alternative CSC guidelines, with consent from all members of our coalition, we chose the New York guidelines ${ }^{2}$ to serve as a model for our work because it took a more equitable and holistic approach to a public crisis. Our priorities were to offer an alternative strategy that eliminated considerations of comorbid conditions and used a modified scoring system that counteracted potential discrimination against people with disabilities.

\section{Engage the community}

With an imminent surge in COVID-19 cases expected within weeks of the initial release of Massachusetts CSC guidelines, we had to work effectively to reach consensus on alternative guidelines and simultaneously to compel State health legislators to change CSC guidelines before they potentially would need to be invoked.

Our group began by mobilising members across sectors that included disability rights advocates, local patient advocacy groups, individuals from Black and Brown communities, physicians of colour, ethicists, state legislative experts and healthcare providers across the state into one unified coalition. Through this multisectoral coalition, we began to explore the challenges posed by the proposed CSC guidelines and created alignment on the fundamental principles of alternative frameworks.

Community members and leaders from marginalised groups were fully engaged in the process of coalition-building, creating an alternative framework and leading discussions on the implications of implementing the CSC guidelines in Massachusetts. The coalition also included physicians from marginalised groups, who worked closely with community members to amplify these efforts.

To demonstrate wide-scale dissatisfaction with the proposed guidelines, we worked through the MCHE to coordinate and circulate a sign-on letter ${ }^{3}$ that was signed by over 400 healthcare providers across the State that delineated the pitfalls of the proposed guidelines. This sign-on letter was included in the press release ${ }^{5}$ that was released by the coalition.

\section{Build legislative coalition}

With in-group alignment among the newly mobilised crosssectoral community of advocates and the alternative policy creation process underway, we initiated legislative coalition building with state and national lawmakers. We partnered with members from the Massachusetts Black and Latino Legislative Caucus to align on the problematic issues identified with the proposed CSC guidelines and to articulate through a press release and a letter to the Governor ${ }^{6}$ the need for revised CSC guidelines. A small group of physician leaders within the Coalition also collaborated with legislators at the City level to advocate for reform during a City Council public hearing ${ }^{7}$ on the potential unwanted and racialised impacts of the CSC guidelines.

\section{Engage the media and educate the broader community}

Our media advocacy platform relied on three distinct domains; targeted social media, earned media pieces written by local news outlets and media appearances on cable broadcast news outlets. Social media interventions were targeted at raising awareness of the issues posed by the proposed State guidelines, building coalitions with politicians who could be allies for this work and announcing press releases or sharing sign-on letters to further aid in our community mobilisation efforts. Social media posts were also targeted at capturing the attention of prominent lawmakers about the CSC guidelines resulting in a series of coordinated press releases by the offices of MA Congresswoman Pressley, ${ }^{8}$ MA Congressman Kennedy and MA State Representative Santiago ${ }^{9}$ arguing against the guidelines on the grounds outlined by the MCHE. Our efforts garnered attention from local reporters who highlighted the concerning issues behind the State's CSC guidelines. ${ }^{10}{ }^{11}$ Finally, individual physicians on our team shined a spotlight on the proposed guidelines through media appearances on local and national news broadcasts and testifying before the Boston City Council. ${ }^{712} 13$

On 20 April 2020, near the height of the pandemic and just under 2 weeks following the initial release of the original MA CSC guidelines, the state of Massachusetts released its revised CSC guidelines. The guidelines were specifically revised 'to prevent unfair discrimination in response to concerns raised by members or representatives of vulnerable and marginalised communities'. Notably, the Massachusetts Department of Health acknowledged the need for close monitoring of the implementation of CSC to ensure equity. As proposed by the MCHE, the consideration of common comorbid conditions was removed entirely from the guidelines. Instead, the revised guidelines proposed that physicians make a judgement for who receives scarce resources based on likelihood of immediate, 1-year, and 5 -year survival. While this change is rife with its own set of challenges and risks for bias, MCHE and its community members view this shift as a significant step in the right direction as the removal of comorbid conditions gives members of marginalised communities a better chance to receive scarce resources. This change to the CSC guidelines also exerts continued pressure on representatives and State officials to revisit CSC guidelines and continue their engagement of the community members, particularly members of marginalised groups, for feedback.

We believe our approach to drawing attention to the needed changes to the Massachusetts CSC was overall successful; however, it was not without its challenges. The novelty of COVID-19 and lack of clinical evidence regarding patient outcomes complicated our ability to suggest alternative strategies for resource allocation with certainty. This will be a continued challenge as we study and learn more about this disease.

Furthermore, during the height of the pandemic, hospitals scrambled to secure and redistribute scarce resources and had little time to consider the downstream effects of implementing CSC on vulnerable communities. The group's coalition building placed an additional strain on well-intentioned individuals already stressed to respond to the on-the-ground effects of the pandemic on the populations they served.

Finally, with the continued growth of our coalition, there was an extension from the implications of CSC guidelines on Black and Latinx communities to other medically marginalised communities; it was important to centralise our mission of 
equity for all medically underserved communities and remain adaptable to the changing needs of our coalition members and the communities we represented.

\section{FUTURE DIRECTION AND CONCLUSION}

MCHE is actively involved in continued efforts for health reform by partnering with local and national organisations to address safe school and business reopenings, housing insecurity, immigration reform, police accountability and racial justice. Future goals include evaluating the effectiveness of our coalition by measuring outcomes and growing partnership with local and state authorities to catalyse policies that foster equity.

Improving healthcare systems and policies is contingent on the creation of coalitions. As a result of our advocacy, the MA CSC guidelines were revised with meaningful effort to address our concerns, though the revised guidelines require ongoing concerted effort to make them equitable for all groups. Our coalition emphasises the power of collective action.

In this article, we discuss strategies for coalition mobilisation in the middle of the COVID-19 pandemic. These strategies can be considered for adoption by other communities committed to health policy reform and equity.

Twitter Onyinyechi F Eke @onyi_eke and Onyeka Otugo @onyeka otugo

Contributors OFE: idea conception, wrote and edited manuscript. AM: wrote and edited manuscript. HK: idea conception, wrote and edited manuscript. 00: idea conception, wrote and edited manuscript. AM: wrote and edited manuscript. JS: idea conception, wrote and edited manuscript. WMK: provided mentorship, wrote and edited manuscript.

Funding The authors have not declared a specific grant for this research from any funding agency in the public, commercial or not-for-profit sectors.

Competing interests None declared.

Patient consent for publication Not required.

Provenance and peer review Not commissioned; externally peer reviewed.

Open access This is an open access article distributed in accordance with the Creative Commons Attribution Non Commercial (CC BY-NC 4.0) license, which permits others to distribute, remix, adapt, build upon this work non-commercially, and license their derivative works on different terms, provided the original work is properly cited, appropriate credit is given, any changes made indicated, and the use is non-commercial. See: http://creativecommons.org/licenses/by-nc/4.0/.

ORCID iD

Onyinyechi F Eke http://orcid.org/0000-0002-7180-4589

\section{REFERENCES}

1 Sabatier PA, Weibel CM. Chapter 7: The Advocacy Coalition Framework. In: Paul Sabatier theories of the policy process. 2nd Edition. Westview Press, 2007: 189-210.

2 New York State Department of Health. New York State Task Force on Life and the Law. Ventilator allocation guidelines.. Available: https://www.health.ny.gov/regulations/ task_force/reports_publications/docs/ventilator_guidelines.pdf [Accessed 31 Jul 2020].

3 Rosen A. As coronavirus cases rise, some healthcare workers urge mass. to change ventilator guidelinesThe Boston Globe. Available: https:/www.bostonglobe.com/ 2020/04/12/metro/state-announces-70-more-deaths-due-coronavirus-2615-newcases/ [Accessed 18 Aug 2020].

4 Open letter to crisis standards of care Advisory Committee. Available: https://docs. google.com/document/d/13kGxuxmlldxbo3X2Kh_i7ruyelSsXBzEiQRL73KK_Vc/edit [Accessed 18 Aug 2020].

5 Physicians and Bioethicists demand equity in guidelines to ration Life- saving ventilators. Available: https://drive.google.com/file/d/1_oHzkoDOR80QaRCeeLFUk 60hONNTNVG6/view [Accessed 18 Aug 2020].

6 MBLLC calls for a pause in the crisis standards of care guidelines, 2020. Available: https://www.mablacklatinocaucus.com/our-work/mbllc-calls-for-a-pause-in-crisesstandards-of-care-guidelines [Accessed 1 Aug 2020].

7 Boston City Council Committee on Public Health. Docket \#0638 Hearing on the proposed guidelines for ventilator distribution and ICU beds in the event of a shortage and ensuring that health disparities do not dictate medical care during the covid-19 pandemic, 2020. Available: https://www.youtube.com/watch?v= wRdZFOK3euE\&feature=youtu.b [Accessed 18 Aug 2020].

8 Nik D-K. Ayanna Pressley urges Charlie baker to rescind guidelines for potentially rationing COVID-19 care. Available: https://www.boston.com/news/politics/2020/ 04/14/ayanna-pressley-massachusetts-crisis-care-standards [Accessed 9 Sep 2020].

9 Christopher G. Mass. lawmakers say the state's ventilator, bed rationing guidelines prioritize whites over patients of color, 2020. Available: https://www.boston.com/ news/local-news/2020/04/10/massachusetts-lawmakers-ventilator-bed-guidelinesrace-coronavirus [Accessed 9 Sep 2020].

10 Andy R. State revises guidelines for who gets ventilators in crisis, following complaints about equity. Available: https://www.bostonglobe.com/2020/04/20/nation/staterevises-guidelines-who-gets-ventilators-crisis-following-complaints-about-equity/ [Accessed 9 Sep 2020].

11 Dialynn D. 'This disease is just crushing communities of color': Emergency room doctors on how COVID-19 is laying bare inequities in health care. Published April 2020.. Available: https://www.boston.com/news/coronavirus/2020/04/24/healthinequities-coronavirus-massachusetts [Accessed 9 Sep 2020].

12 Vanessa W. Mgh doctor opens up about struggles with overload of patients, lack of ventilators. Available: https://www.boston25news.com/news/mgh-doctor-opensup-about-struggles-with-overload-patients-lack-ventilators/WXC2SNMBWVFQRJAB WFSMQUS50Q/ [Accessed 9 Sep 2020]

13 Yamiche A. 'We're angry and we're hurting.' Why communities of color suffer more from COVID-19. Available: https://www.pbs.org/newshour/show/were-angry-andwere-hurting-why-communities-of-color-suffer-more-from-covid-19 [Accessed 9 Sep 2020]. 